\title{
Teaching research: a programme to develop research capacity in undergraduate medical students at the University of KwaZulu-Natal, South Africa
}

Stephen E. Knight ${ }^{1 *}$, Jacqueline M. Van Wyk ${ }^{2}$ and Saajida Mahomed ${ }^{3}$

\begin{abstract}
Background: Improved research ability is a core competency to achieve in health professionals. The Selectives is a three-year, longitudinal, community-based programme within the undergraduate curriculum which aims to develop research capacity in all medical students during the prescribed curriculum. In relation to the programme, the authors describe the types of studies conducted by students, conditions that facilitated their learning, how the experience improved students' knowledge of research and public health and their development of reflective learning practices.
\end{abstract}

Methods: A cohort of 212 students completed the Selectives Programme in 2014, and 69 (32\%) completed an anonymous online evaluation thereafter. Data collected include students' perceptions of the research component of Selectives; its impact on their knowledge of research and a documentary analysis of their research protocols and posters. Ethical approval for the ongoing evaluation of the Selectives was sought and obtained from the institutional Biomedical Research Ethics Committee.

Results: During Selectives, 75 groups of 2-4 students conducted research studies of primary health care problems in community settings. Each group is assessed on their presentation of research findings as a scientific poster. The Selectives facilitated learning for the majority of the cohort. Students reported positive learning experiences about the research process, including ethics; protocol writing; data processing; dissemination of findings and results; and their use in informing a health promotion intervention. Students reported having gained a better understanding of their strengths and weaknesses through reflective learning from this academic activity. The Selectives is scheduled adjacent to the students' mid-year vacation. This scheduling together with the placement in the students' home community minimizes travel and accommodation costs associated with working outside the academic teaching platform and therefore makes it a cost-effective model in a low resource context.

Conclusions: The Selectives has proven beneficial to develop a range of generic and practical research competencies for a full cohort of students enrolled in the undergraduate medical curriculum. The Selectives research process is integrated with learning about population health and the social determinants of health in a primary health care setting.

Keywords: Community-based curriculum, Community-oriented primary care, Reflective learning

\footnotetext{
* Correspondence: knights@ukzn.ac.za

${ }^{1}$ School of Nursing and Public Health, College of Health Sciences, University

of KwaZulu-Natal, Room 217 George Campbell Building, Durban 4041, South

Africa

Full list of author information is available at the end of the article
} 


\section{Background}

Aging, a lack of effective training and inadequate exposure to research opportunities for medical students are factors that have contributed to the global and local decline in the number of physician scientists, those who know and apply scientific method to study clinical or health related issues [1-4]. There are furthermore limited resources for the development of these competencies in countries faced with human resource constraints, a huge burden of disease and critical health system challenges [5].

The imperative to improve medical students' research capacity and reflective learning is one of three educational concerns for medical schools globally $[6,7]$. The other priorities are to improve students' understanding of population health $[6,8]$ and their knowledge of the 'upstream' or social determinants of health and disease $[8,9]$.

The call to improve 'scholarship' in healthcare professionals is one of the attributes being advanced by the Health Professions Council of South Africa (HPCSA) [8]. This attribute encompasses a range of aptitudes linked to the research process, evidence-based practice, health promotion, educating patients and communities, and the development of reflective learning (Table 1).

Early exposure of undergraduate medical students to practical research activities and capacity development have been linked to improved attitudes and scholarship.
These students are more likely to pursue researchrelated careers [10] and become physician scientists, [11] [10] which promotes scientific output [11, 12]. A better understanding of research can help the development of higher order learning such as critical-thinking, problem solving, interpreting data and communicating research findings $[10,13,14]$. For clinicians the benefits of improved research capacity and use of evidence-based approaches for decision making should result in better clinical care, safety and competency [15]. These benefits justify the integration of research teaching into medical curricula [15].

Barriers to research training in undergraduate curricula such as a lack of initiative (exposure, experience and knowledge), impulse (time and competitive environment), incentive (presentation/publication opportunities and acknowledgement) and idols (mentors and supervisors) had been highlighted in the 'Four I's' framework of Scaria [5]. All these factors are very real challenges especially in resource constrained setting when constructing authentic medical curricula which incorporate research training.

A variety of methods have been used to teach research. These include problem-based curricula, research electives, compulsory research projects, and programmes for volunteers and the facilitation of research training by charitable non-governmental organisations. Many initiatives to improve research capacity are 'add-ons' for

Table 1 Selectives programme research activities aligned to HPCSA scholarship competencies

\begin{tabular}{|c|c|}
\hline Scholarship competencies & Research outcomes \\
\hline \multirow{4}{*}{$\begin{array}{l}\text { - Phrase a clear, answerable, relevant research question } \\
\text { related to clinical practice. } \\
\text { - Locate, critically evaluate and interpret relevant \& } \\
\text { previous research findings from robust sources. }\end{array}$} & Module 1 ( $2^{\text {nd }}$ year $)$ \\
\hline & $\begin{array}{l}\text { 1. Formulate a research question (based on a practice } \\
\text { profile \& community diagnosis) in a PHC setting }\end{array}$ \\
\hline & 2. Literature review \\
\hline & 3. Reflective learning \\
\hline \multirow{10}{*}{$\begin{array}{l}\text { - Consider the applicability of research, understand research design, } \\
\text { analysis, and research ethics, consider patient autonomy, respect } \\
\text { plagiarism, confidentiality and ownership of intellectual property. } \\
\text { - Create, apply, translate and disseminate knowledge. }\end{array}$} & Module 2 ( $3^{\text {rd }}$ year $)$ \\
\hline & 1. Prepare a research protocol \\
\hline & -Online ethics certificate \\
\hline & -Prepare a questionnaire \\
\hline & 2. Obtain ethical approval from IRB \\
\hline & 3. Conduct fieldwork with informed consent \\
\hline & 4. Process data \\
\hline & 5. Prepare scientific poster \\
\hline & - Present poster to peers \\
\hline & 6. Reflective learning \\
\hline \multirow[t]{5}{*}{ - Demonstrate a lifelong commitment to reflective learning. } & Module 3 ( $4^{\text {th }}$ year $)$ \\
\hline & 1. Prepare health promotion intervention informed by research findings \\
\hline & 2. Implement and evaluate the intervention \\
\hline & 3. Reflect on lessons learnt \\
\hline & 4. Orientate incoming $2^{\text {nd }}$ year students to the Selectives research \\
\hline
\end{tabular}


academically talented medical students [16], such as the United Kingdom based extracurricular student-led national collaborative research training initiative $[17,18]$ or are part of student selected components (SSC's) of learning [19].

Locating population-based research training within primary health care (PHC) settings advances the social accountability agenda [20]. There are, however, limited descriptions of innovative ways to engage students in 'real-life' population-based PHC research and even fewer that link research training to a community-based academic programme [16].

Precedence should thus be given to academic activities that integrate research into the curriculum, incorporate reflective learning, and create an awareness of a population perspective on clinical problems and the influence of the social determinants on health and disease.

A theme advanced by the Medical Education Priority Initiative (MEPI) [21] is the development of research capacity for health care professionals by facilitating locally relevant research training that would augment national research capacity, faculty development and retain researchers in Africa [22-25]. Against this background, the MEPI project at the University of KwaZulu-Natal (UKZN), South Africa [21] has encouraged the development of scholarship and research training for health professionals and specifically medical students [21, 22].

Research teaching and practice at UKZN, has been integrated with PHC clinical teaching in the six year undergraduate medical curriculum. In the next section we provide an overview of the Selectives, with a particular focus on the research process. In the rest of the paper, we present the types of studies conducted by medical students, conditions that facilitated their learning and how the experience improved their knowledge and perceptions of research and public health, and their development of reflective learning practices in the Selectives.

\section{The selectives programme at UKZN}

Using the Community-Oriented Primary Care (COPC) approach the Selectives aims to develop medical students who are responsive to the needs of local communities and who will become socially accountable and transformative agents of change in the struggling South African healthcare system (Fig. 1). Moving from the traditional disease focused approach, COPC responds to measured community needs that are addressed through PHC interventions including the 'upstream' and social determinants of health [26].

The Selectives comprises three, 4-week modules in the second, third and fourth academic years of the undergraduate medical curriculum (Fig. 1). Successful completion of these modules is a pre-requisite for graduating from the medical programme. Clear learning outcomes are prescribed in the curriculum that include the research process and incorporate 'scholarship' competencies (Table 1).

The 4-week period is scheduled to follow the students' mid-year vacation. This together with the location in the students' home community minimizes travel and accommodation costs associated with working outside the academic teaching platform and therefore makes it a costeffective model in a low resource context.

Students choose their own Selectives site, usually near their home town, and work in self-selected

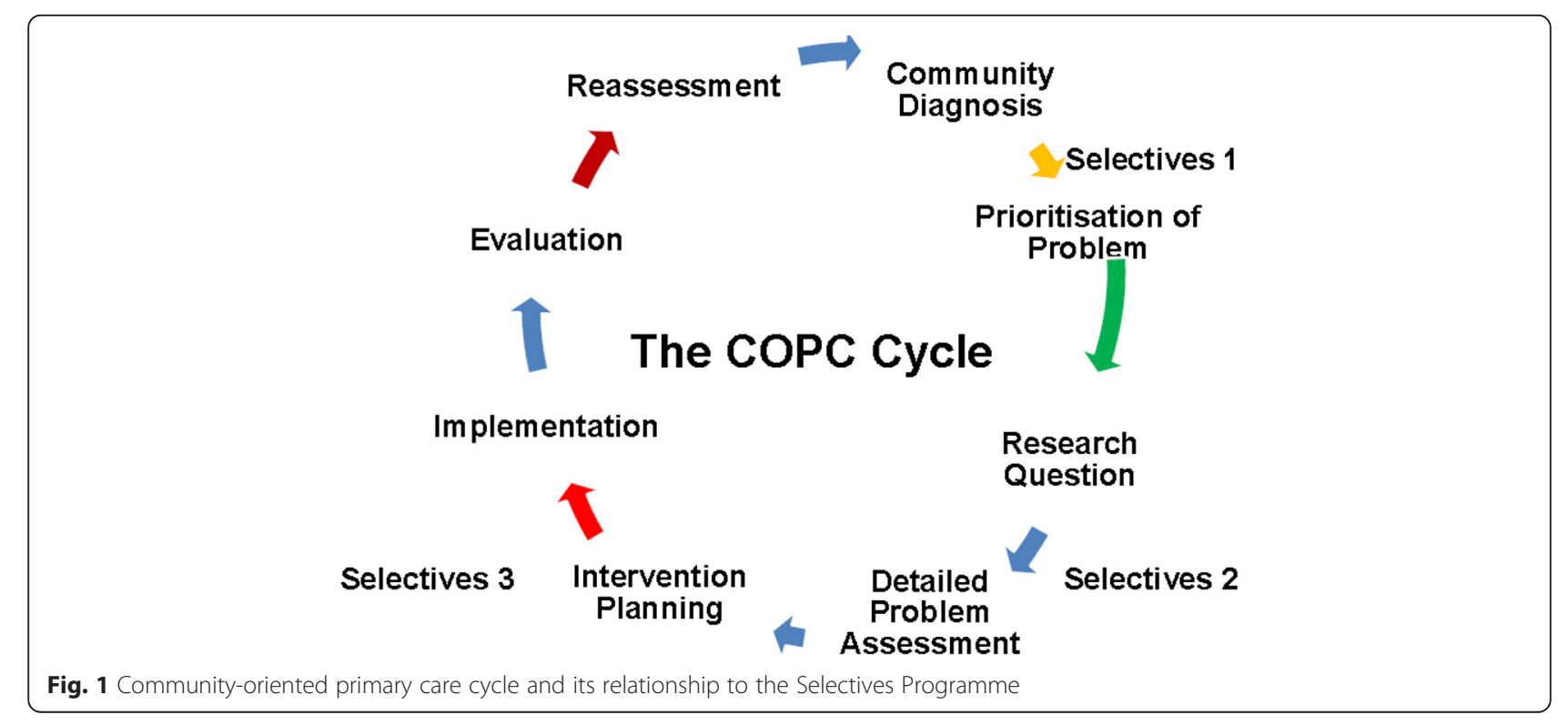


groups of two to four. In the first Selectives module they make a community diagnosis [27] based on a 'practice profile' [28] of the PHC patient consultations they observe. From this they formulate a relevant PHC research question. Each student then prepares a referenced literature review around the selected research topic. During the second Selectives module in the $3^{\text {rd }}$ academic year each group prepares a research protocol informed by structured lectures and tutorials on basic research methods. A quiz, testing knowledge and application of basic epidemiological concepts including descriptive biostatistics and research methods, is administered before and after a week of lectures to assess students' learning.

The research protocols are submitted to the institutional ethics review board (IRB) for approval. To facilitate the approval of a large number of undergraduate research studies, the IRB limits the scope of research to questions of a non-sensitive nature and study participants from non-vulnerable populations. With informed consent, data is collected on a custom-designed questionnaire from at least 100 participants in the Selectives Site community. Data from the questionnaire is processed and presented as a scientific research poster to peers and examiners. In the third Selectives module in the $4^{\text {th }}$ year a health promotion activity informed by the research findings is implemented thus closing the research cycle (Fig. 1).

\section{Methods}

An observational descriptive case-study of the Selectives research training for medical students at UKZN was conducted. Some basic demographic variables and the research topics, protocols, and posters produced by this cohort of medical students were analysed. The students, who concluded Selectives in 2014, were reminded on three occasions to complete an anonymous online (Google Forms) custom-developed evaluation questionnaire(Additional File 1). Both quantitative and qualitative data were collected, which enabled students to reflect on their experiences of learning about health research. Questions covered aspects of scholarship and the research process specified in the HPCSA framework. In addition, the questionnaire elicited responses from students about their understanding of research, evidencebased medicine and reflective learning (Table 1). The questionnaire used a 5-point Likert scale to quantify students' responses. The students' responses to the stated items were re-categorised as: "Agree"; "Neither agree nor Disagree"; and "Disagree" for ease of reporting. The qualitative data were analysed thematically to determine students' experience and learning with reference to the HPCSA research framework.
Ethical approval for the ongoing evaluation of the Selectives was sought and obtained from the Biomedical Research Ethics Committee of the UKZN (R201/04).

\section{Results}

The cohort of 212 medical students completed all the requirements of the three Selectives modules in 2014. Most were female (62\%), Black African (70 \%) with an average age of 22 years. Students were from areas categorised as rural (37\%), peri-urban or township (27\%) and urban $(36 \%)$. The areas where they chose to conduct research reflected the locations of their home categories i.e. (39\% rural, $29 \%$ peri-urban and $32 \%$ urban respectively). This is supported by $83 \%$ of the class indicating that they had slept at home during the Selectives period as compared to $29 \%$ who normally sleep at home during term-time.

Each of the students gained in knowledge and application of epidemiological concepts and research methods based on their improved performance in a pre-and posttest (mean: $57 \%$ to $69 \%$ respectively); completed an online ethics certificate; and wrote a literature review. All 75 groups submitted a research study protocol for review and approval, conducted research and presented their results as a scientific poster to peers and faculty members for assessment. When asked about the quality of the protocols, the IRB reviewers commented that many were "better than average." The scope of topics researched by students reflects the common presenting problems in PHC facilities in KZN (Table 2). Most of the research questions surveyed aspects relating to

Table 2 Research topics (number) studied by 66 medical student groups in primary health care contexts

\begin{tabular}{ll}
\hline Non-communicable & Hypertension (30) \\
Disease (50) & Diabetes (10) \\
& Alcohol (3) \\
& Musculoskeletal (2) \\
& Epilepsy (2) \\
& Mental health (2) \\
& Gastro-intestinal (1) \\
& Tuberculosis (4) \\
HIV, AIDS and TB (9) & Sexually transmitted infections (1) \\
& Safe sex (3) \\
& Pregnancy (1) \\
Maternal \& Child Health (5) & Cxpanded Program on Immunisation (2) \\
& Contraceptives (1) \\
& Nutrition (1) \\
& Diarrhoea (1) \\
& Gender Based Violence (1) \\
Injury \& Violence (2) & Motor vehicle collisions and alcohol use (1) \\
\hline
\end{tabular}


patients' knowledge and management of a disease (particularly lifestyle modification), and adherence to medicines.

Sixty nine (32\%) students completed the final Selectives evaluation. The demographic profile of the respondents reflected the diversity of the cohort. The perceptions and experiences of the respondents attest to their increased knowledge and understanding of research (Fig. 2).

The Selectives experience allowed respondents opportunities to learn about research and to gain practical research skills. Students gained a better understanding of both the research methods and process. They improved their understanding of epidemiology and of descriptive biostatistics. Their reported awareness of plagiarism, intellectual property, ethics and study participant confidentiality had increased. These students also developed skills in accessing and appraising literature relevant to their research topics; processing and analysing data; and writing and presenting evidence-based reports. From the health promotion interventions conducted, they appreciated the applicability of research findings. Qualitative comments attest to students' learning in the five Scholarship competencies (Table 3).

During the Selectives modules the students also learned about reflective practice. They valued the feedback received from their peers and perceived the group process as supportive of their learning. The majority of the respondents reported that the Selectives had offered them sufficient opportunities to learn and practice self-reflection.
Most students valued the learning platform provided by the community-based sites as it assisted them in measuring the burden of disease; applying clinical epidemiology while gathering authentic patient information; developing knowledge and skills to evaluate the PHC services; and in understanding the role of the practitioners who rendered services on the platform. The Selectives further developed generic skills including time management; teamwork, self-directed learning and the use and application of information technology which is essential to successful research.

The best research posters and presentations are awarded prizes. A number of groups have presented their research at National and local College Research meetings. Two groups have prepared Scientific Letters to local journals and most groups gathered data of sufficient quality to do this with appropriate motivation and support [29]. Students are encouraged to display their research posters at clinics in the Selectives sites.

\section{Discussion}

During Selectives students conduct authentic research in community-based and decentralized learning settings. A unique feature of this programme is the location of the research setting i.e. within the home community of the student. The community-based placement and timing of the Selectives facilitates the teaching and supervision by a multi-professional team of teachers outside the faculty addressing the recommendation of the Frenk report, which requires health professions education to be more PHC focused [6]. In line with the goal to encourage and

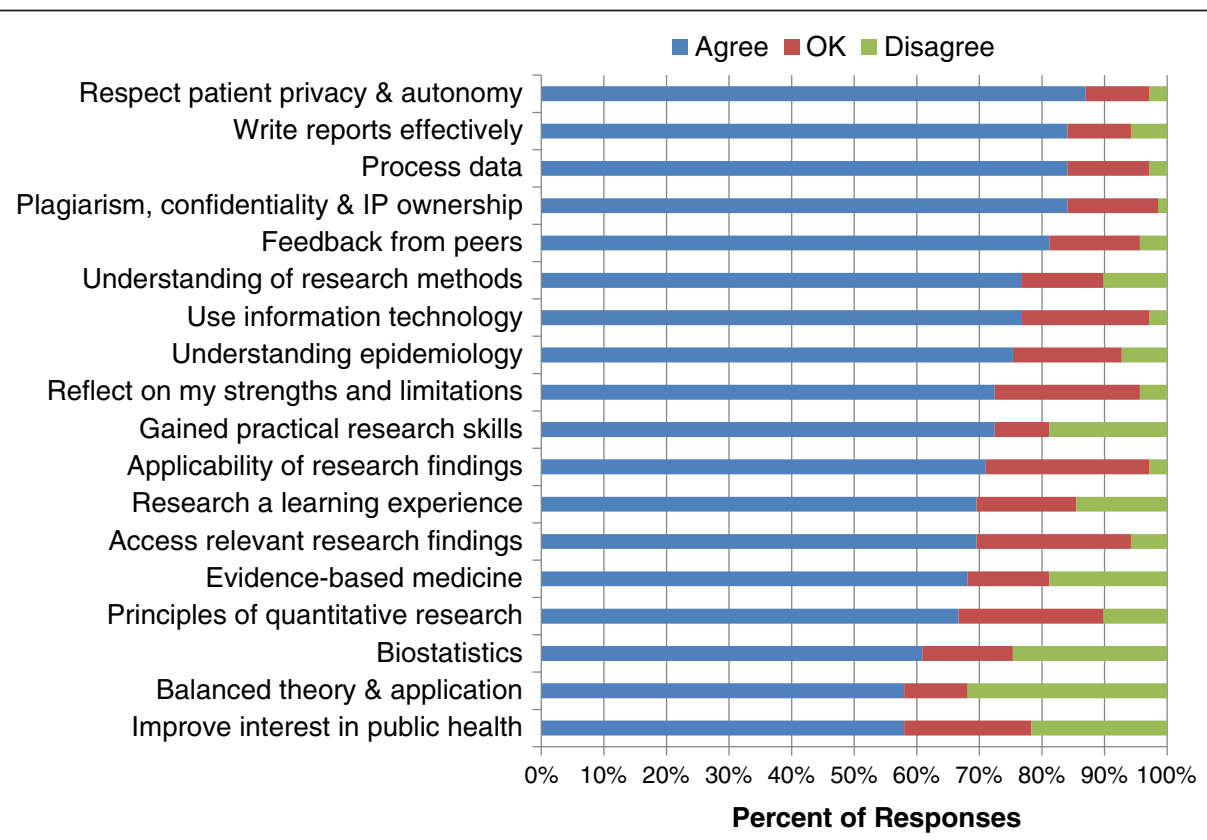

Fig. 2 Responses of medical students $(N=69)$ to statements about Selectives research training at UKZN 
Table 3 Students' comments of the selectives programme development of their scholarship competencies

\begin{tabular}{|c|c|}
\hline Scholarship competency & Students' qualitative comments \\
\hline $\begin{array}{l}\text { Phrasing clear, answerable, relevant research questions } \\
\text { related to clinical practice. }\end{array}$ & $\begin{array}{l}\text { - [The Selective helped me in...] identifying common problems and } \\
\text { doing research on this in the community }\end{array}$ \\
\hline $\begin{array}{l}\text { Locating, critically evaluating and interpreting relevant } \\
\text { \& previous research findings from robust sources }\end{array}$ & - Learning how to [conduct] and write a literature review \\
\hline $\begin{array}{l}\text { Considering the applicability of research, understanding } \\
\text { research design, analysis, research ethics, consider patient } \\
\text { autonomy, respect plagiarism, confidentiality and ownership } \\
\text { of intellectual property. }\end{array}$ & $\begin{array}{l}\text { - The Selectives has given us abilities and skills in research that we } \\
\text { would not have gained anywhere else in our medical curriculum } \\
\text { and even some qualified doctors don't have and are shocked that } \\
\text { we have such a good approach to research } \\
\text { - Health promotion based on what we found in the research }\end{array}$ \\
\hline Creating, applying; translating and disseminating knowledge. & $\begin{array}{l}\text { - Able to apply the knowledge that I have learnt on the classroom } \\
\text { in a real clinical setting } \\
\text { - I improved my presentation skills } \\
\text { - It was great publishing our research in a journal }\end{array}$ \\
\hline Demonstrating a lifelong commitment to reflective learning. & $\begin{array}{l}\text { - I felt like we made a difference during the health promotion intervention. } \\
\text { - It helped me to reflect on myself as a clinician, I liked the use of the Gibbs } \\
\text { [reflective learning] Cycle. } \\
\text { - Valued the constructive feedback from peers and lecturers on our health } \\
\text { promotion intervention }\end{array}$ \\
\hline
\end{tabular}

advance health professional education and training in decentralized, rural training sites, we believe the success of the Selectives lies in the fact that two thirds of students conducted research in sites situated in rural or disadvantaged communities [30].

In this programme research capacity development is integrated into the curriculum and the completion of the research modules is a prerequisite for graduation. The importance and mandatory inclusion of research training in undergraduate curricula has been highlighted by the Boyer Commission on Educating Undergraduates in the Research University [31, 32]. In Germany the completion of a dissertation is required before students can be awarded their medical degree [31]. Only a small proportion of these German medical students successfully complete the thesis during their clinical training and it was proposed that basic training in scientific research methodology should become an integrated part of their medical curriculum [33].

Students recognise the benefits of research experience $[19,34,35]$. In the Selectives, students highly valued the research experience for exposing them to translational research in a manner that is inseparable from patient contact and clinical care. The experience is believed to be efficient as it also informed subsequent health promotion interventions planned by the students. The Selective thus provides an authentic and useful research experience to respond to a challenge to include research training in the design of the modern medical curriculum.

Each group presented their research in a setting that simulated the process following the acceptance of an abstract by a peer-reviewed scientific conference. Poster sessions are time tabled and students present to faculty, site supervisors and peers. For some, the quality of the research has also been of sufficient standard for dissemination as indicated by those accepted for publication in peer reviewed journals [29]. This finding probably attests to the skills of their faculty supervisors and their guidance to the completion of the research cycle. The quality of the UG student research is different to a survey conducted at the University of Cape Town, where staff perceived student research as substandard and not worthy of presentation [3].

However, there are challenges in securing adequate numbers of suitably trained faculty supervisors to guide the groups. Due to the bulky nature of medical curricula and the off-site location of the implementation of the research, groups and supervisors complain of time pressures to prepare the research protocols and posters within short deadlines. The majority of students accepted on the medical programme are first time tertiary education entrants with limited prior research exposure and many are English second language users. For some these barriers impact on the quality of their research outputs.

The students in our study completed 'real research' and perceived themselves as more experienced in information retrieval and writing skills. This finding resonates with others who compared the perceptions of students in research tracks to those who participated in basic skills electives or lecture-based courses [36]. Previous studies also suggests that medical students with research experience in primary care settings are more likely to pursue research related careers and thus more uniquely placed to conduct population-based studies [10]. Yet, in the absence of literature describing innovative ways to engage students in population-based primary care research, it is hoped that this study will encourage health professions educators in similar resource constrained settings. 
The Selectives emphasises active and student-centred learning and equips students with skills for evidencebased research and practice of EBM. By addressing the barriers as highlighted in the 'Four I's' framework, [5] the Selectives programme successfully addresses each of the barriers and promotes social accountability that facilitates students' transition to becoming transformative learners.

Although the proportion who completed the end of programme questionnaire was low, the demographic profile of the respondents reflected that of the cohort. The level of response is also in keeping with the average rate reported for "end of module" evaluations on the undergraduate programme.

The sustainability of the Selective relates to the feasible costing, incremental and longitudinal research exposure for every undergraduate student in a primary health setting that is curriculated.

\section{Conclusions}

The Selectives Programme is an effective way to develop and incorporate research training; at minimal cost to the faculty, for undergraduate medical students in community-based (de-centralized) PHC learning platforms. This community engagement early in the curriculum extends the learning platform, exposes students to a variety of PHC facilitators and learners play a more active role in their learning. The Selectives enabled students to integrate their community and population perspective and clinical training using the COPC cycle. The longitudinal acquisition of knowledge and skills through researching authentic PHC problems in their 'home' communities has been beneficial to students' understanding of local needs and exposes them to the advocacy role as possible change agents for the community. Students use the findings of their research to implement appropriate health promotion interventions according to identified needs.

The Selectives Programme has evolved into the current format over the last decade and there is a need for a more systematic process to benchmark students' gain in research experience. Further research with communities and healthcare workers at clinics will help us understand the extent to which research and interventions by undergraduate students are beneficial to the PHC providers and communities. Graduate tracking is essential to assess the number of health care workers who become physician-scientists as a result of being taught research as undergraduate medical students.

\section{Ethical approval}

Ethical approval for the study was sought and obtained from the Biomedical Research Ethics Committee of the UKZN (R201/04).

\section{Additional file}

\section{Additional file 1: Questionnaire. (PDF $110 \mathrm{~kb}$ )}

Competing interests

The authors declare that no competing interests exist.

\section{Authors' contributions}

SK developed the model for teaching research to undergraduate medical students described in this paper and prepared the manuscript. JVW holds the ethical approval and contributed substantially to the writing. SM coordinated the teaching of the module in 2014 and contributed to the paper. All authors read and approved the final manuscript.

\section{Authors information}

SK is a public health physician and lecturer responsible for teaching a population perspective for undergraduate medical students, which includes research capacity at the Nelson R Mandela School of Medicine in South Africa. JVW is a medical education consultant and lecturer in the School of Clinical Medicine. SM is a public health physician and lecturer responsible for coordinating the research component in 2014

\section{Acknowledgements}

The authors wish to thank the students who evaluated this programme, the Selectives supervisors, site facilitators and support from the University of KwaZulu-Natal Medical Education Partnership Initiative.

The contents of this article are solely the responsibility of the UKZN MEPI program and do not necessarily represent the official views of the US government.

\section{Funding}

This publication was made possible by grant number: 5R24TW008863 from the President's Emergency Plan for AIDS Relief (PEPFAR), and the Office of Global AIDS Coordinator and the U. S. Department of Health and Human Services, National Institutes of Health (NIH OAR and NIH OWAR).

\section{Author details}

${ }^{1}$ School of Nursing and Public Health, College of Health Sciences, University of KwaZulu-Natal, Room 217 George Campbell Building, Durban 4041, South Africa. ${ }^{2}$ School of Clinical Medicine, University of KwaZulu-Natal, Durban, South Africa. ${ }^{3}$ School of Laboratory and Laboratory Medicine, College of Health Sciences, University of KwaZulu-Natal, Durban, South Africa.

Received: 2 October 2015 Accepted: 26 January 2016

Published online: 16 February 2016

\section{References}

1. Lemoine NR. The clinician-scientist: a rare breed under threat in a hostile environment. Dis Model Mech. 2008;1(1):12-4.

2. Mayosi BM, Dhai A, Folb P. Consensus Report on Revitalising Clinical Research in South Africa a Study on Clinical Research and Related Training in South Africa. Pretoria: Academy of Science of South Africa; 2009. 174-175 p. Retrieved: March 10, 2015. Available from: http://www.assaf.co.za/wpcontent/uploads/2009/09/ASSAf-Clinical-Report-2009.pdf.

3. Nel D, Burman RJ, Hoffman R, Randera-Rees $S$. The attitudes of medical students to research. S Afr Med J. 2014;104(1):33-6.

4. Roberts SF, Fischhoff M, Sakowski S, Feldman EL. Transforming science into medicine: How clinician-scientists can build bridges across research's "valley of death". Acad Med. 2012:87(3):266-70.

5. Scaria V. Whisking research into medical curriculum. Calicut Med J. 2004;2(1):e1. Retrieved: 10 March 2015 Available from: http://www.calicutmedicaljournal.org/ 2004/2/1/e1/index.html.

6. Frenk J, Chen L, Bhutta ZA, Cohen J, Crisp N, Evans T, et al. Health professionals for a new century: Ttransforming education to strengthen health systems in an interdependent world. Lancet. 2010;376(9756):1923-58.

7. Gillam S, Maudsley G. Public health education for medical students : rising to the professional challenge. J Public Health (Bangkok). 2009;32(1):125-31

8. Health Professions Council of South Africa. Medical And Dental Professions Board: Core competencies for undergraduate students in clinical associate, dentistry and medical teaching and learning programmes in South Africa. Pretoria: Health Professions Council of South Africa; 2014. 
9. Manchanda R. The Upstream Doctors: Medical Innovators Track Sickness to Its Source. TED Books, Published in partnership with Simon \& Schuster, New York 2013.

10. Solomon SS, Tom SC, Pichert J, Wasserman D, Powers AC. Impact of medical student research in the development of physician-scientists. J Investig Med. 2003;51(3):149-56.

11. Fang D, Meyer R. Effect of two Howard Hughes Medical Institute research training programs for medical students on the likelihood of pursuing research careers. Acad Med. 2003;78(12):1271-80.

12. Abu-zaid A, Alkattan K. Integration of scientific research training into undergraduate medical education: a reminder call. Med Educ Online. 2013; 18(1):22832. doi:10.3402/meo.v18i0.22832.

13. Khan H, Khawaja MWA, Khan H, Khawaja MR, Waheed A, Rauf MA, et al. Knowledge and attitudes about health research amongst a group of Pakistani medical students. BMC Med Educ. 2006;6(54):54. Retrieved: 21 September 2015 http://www.biomedcentral.com/1472-6920/6/54.

14. Wong J et al. SDPS. A survey on the attitudes towards research in medical. BMC Med Educ. 2010;10(4):1-7.

15. Pruskil S, Burgwinkel P, Georg W, Keil T, Kiessling C. Medical students' attitudes towards science and involvement in research activities: a comparative study with students from a reformed and a traditional curriculum. Med Teach. 2009;31(6):e254-9.

16. De Haven M, Chen L. Teaching Medical Students Research While Reaching the Underserved. Fam Med. 2005;37(5):315-7.

17. Chapman SJ, Glasbey JCD, Khatri C, Kelly M, Nepogodiev D, Bhangu A, et al. Promoting research and audit at medical school: evaluating the educational impact of participation in a student-led national cohort study. BMC Med Educ. 2015;15(1):326. Retrieved: 29 November 2015 Available from: https:// bmcmededuc.biomedcentral.com/articles/10.1186/s12909-015-0326-1.

18. Bhangu A, Fitzgerald JE, Kolias AG. Trainee-led research collaboratives: a novel model for delivering multi-centre studies. ANZ J Surg [Internet]. 2014; 84(12):902-3. Retrieved: 20 December 2015 Available from: http://doi.wiley. com/10.1111/ans.12797.

19. Murdoch-Eaton D, Drewery S, Elton S, Emmerson C, Marshall M, Smith JA et al. What do medical students understand by research and research skills? Identifying research opportunities within undergraduate projects. Med Teach. 2010;32(3):e152-60.

20. Gonzales AO, Westfall J, Barley GE. Promoting medical student involvement in primary care research. Fam Med. 1998;30(2):113-6.

21. Lalloo UG, Bobat RA, Pillay S, Wassenaar D. A strategy for developing future academic leaders for South Africa in a resource-constrained environment. Acad Med. 2014;89(Supplement):S55-9.

22. Glass RI, Razak MH, Said M. The Importance of Research in the MEPI Program: Perspectives From the National Institutes of Health. Acad Med. 2014;89(8 Suppl):S9-10

23. Mullan F, Omaswa F, Frehywot S. Preface. Acad Med. 2014;89(8):S3.

24. Mashaah T, Hakim J, Chidzonga M, Kangwende RA, Naik Y, Federspiel N, et al. Strengthening research governance for sustainable research: experiences from three zimbabwean universities. Acad Med. 2014;89(8 Suppl):S69-72.

25. Olaleye DO, Odaibo GN, Carney P, Agbaji O, Sagay AS, Muktar H, et al. Enhancement of Health Research Capacity in Nigeria Through North-South and In-Country Partnerships. Acad Med. 2014;89(Supplement):S93-7.

26. Abdurahman K, Harden R, Mennin S. International Handbook of Medical Education: Global perspectives and Best practices. Routledge; Oxford 2015.

27. Crouse QS. Teaching community diagnosis: integrating community experience with meeting graduate standards for health educators. Health Educ Res. 1999:14(5):685-96.

28. Public Health England. National General Practice Profile. Department of Health. 2013. Retrieved: April 21, 2015. Available from: fingertips.phe.org.uk/ profile/general-practice

29. Khothatso T, Moshoeshoe T, Saroni Z, Ross A. Knowledge of hypertensive patients about treatment in the Seboche hospital, 2013. South African Fam Pract. 2015;2015:6-8. Retrieved: 13 November 2015. http://dx.doi.org/10. 1080/20786190.2014.976959.

30. Goosby EP, von Zinkernagel D. The Medical and Nursing Education Partnership Initiatives. Acad Med. 2014;89(Supplement):S5-7.

31. Boyer Commission. Reinventing undergraduate education: A blueprint for America's research universities. Boyer Commission on Educating Undergraduates in the Research University Stony Brook NY. 1998. Retrieved: May 21, 2015. Available from: http://eric.ed.gov/?id=ED424840 .
32. Katkin W. The Boyer Commission Report and ItsImpact on Undergraduate Research. New Dir Teach Learn. 2003:93:19-38.

33. Kuhnigk O, Bothern A, Reimer L, Böthern AM, Reimer J, Schäfer I, et al. Benefits and pitfalls of scientific research during undergraduate medical education. GMS Z Med Ausbild. 2010;27(5):Doc72.

34. Imafuku R, Saiki T, Kawakami C, Suzuki Y. How do students' perceptions of research and approaches to learning change in undergraduate research? Int J Med Educ. 2015;6:47-55.

35. Oliveira CC, de Souza RC, Abe EHS, Silva Móz LE, de Carvalho LR, Domingues MAC. Undergraduate research in medical education: a descriptive study of students' views. BMC Med Educ. 2013;14:51. Retrieved: 29 November 2015. http://www.ncbi.nlm.nih.gov/pmc/articles/ PMC4021277/?tool=pmcentrez.

36. Zee $M$, de Boer $M$, Jaarsma ADC. Acquiring evidence-based medicine and research skills in the undergraduate medical curriculum: three different didactical formats compared. Perspect Med Educ. 2014;3:357-70.

\section{Submit your next manuscript to BioMed Central and we will help you at every step:}

- We accept pre-submission inquiries

- Our selector tool helps you to find the most relevant journal

- We provide round the clock customer support

- Convenient online submission

- Thorough peer review

- Inclusion in PubMed and all major indexing services

- Maximum visibility for your research

Submit your manuscript at www.biomedcentral.com/submit
) Biomed Central 